\title{
THE GENESIS OF KIMBERLITE CONCENTRATE XENOCRYSTIC SPINELS
}

\author{
Leon R.M. Daniels
}

Tawana Resources N.L., P.O. Box 10775, Tatitown, Botswana.

\section{INTRODUCTION}

Spinels are commonly found in the heavy mineral concentrates of kimberlites and have long been suggested to be potentially important in the field of diamond exploration (Mal'kov and Popova, 1972). Lawless (1974), in what was probably the most extensive general investigation of South African kimberlite concentrate compositions at the time, documented the concentrate spinel compositions from several southern African kimberlites. It was noted that there was a similarity between the compositions of spinels occurring as inclusions in diamonds and some of the spinels derived from kimberlite concentrates. Apart from concluding that the chromian concentrate spinels, particularly euhedral spinels, are unlikely to have been derived from spinel-lherzolites, Lawless also concluded that both the high chromian ( $>60 \mathrm{wt} \%$ $\mathrm{Cr}_{2} \mathrm{O}_{3}$ ) concentrate spinels and spinel inclusions in diamonds suggested a paragenesis in a chrome-rich environment.

Griffin et al. (1994) used an integrated major- and trace-element approach to define two distinct populations of chromian spinel macrocrysts in kimberlites. The one population was observed to be significant in both Group I and Group II kimberlites from southern Africa and was considered to be derived from disaggregated dunites, harzburgites and subordinate lherzolites. A second major population was found to be present in Group II kimberlites and proposed to be a magmatic population representing high-P phenocrysts in the kimberlite magma.

Analysis of spinel major elements and their interrelationship confirm the presence of at least two significant spinel populations in kimberlite concentrate macrocryst populations. In particular, the concentration of titanium, and the relationship between $\mathrm{TiO}_{2}$ and $\mathrm{Al}_{2} \mathrm{O}_{3}$ and $\mathrm{TiO}_{2}$ and $\mathrm{Cr}_{2} \mathrm{O}_{3}$ may be used to define between the populations. However, the available evidence disputes a phenocrystal relationship with the host kimberlite for the magmatic population. The magmatic population is proposed to be indicative of a mantle melting event that is a pre-requisite for the presence of diamond inclusion type spinels.

\section{SAMPLES}

The majority of the spinels reviewed here were obtained from the concentrates of four kimberlites from southern Africa. Kao and Koffiefontein are Group I kimberlites while Newlands and Dokolwayo are Group II kimberlites. The kimberlites have a wide geographic distribution over southern Africa and are therefore considered to be representative of the Kaapvaal Craton. All the kimberlites are diamondiferous and only Kao has not been extensively mined. The spinels from these five kimberlites were part of the spinel populations investigated by Griffin et al. (1994). The spinels studied generally ranged in size from $0.425-2.0 \mathrm{~mm}$. A few spinels from the Dokolwayo kimberlite exceeded $2.0 \mathrm{~mm}$ in diameter.

\section{RESULTS}

There is no significant discernable difference between the spinel populations with respect to $\mathrm{MgO}$ content. The average compositions of the spinels from the four kimberlites are presented in Table 1. The spinels from the Kao kimberlite have the lowest average $\mathrm{Cr}_{2} \mathrm{O}_{3}$ content $\left(55.33 \mathrm{wt} \% \mathrm{Cr}_{2} \mathrm{O}_{3}\right.$ ) while the Dokolwayo kimberlite spinels have exceptionally high $\mathrm{Cr}_{2} \mathrm{O}_{3}$ content (average $63.84 \mathrm{wt} \%$ ) with a maximum of 73.5 wt $\% \quad \mathrm{Cr}_{2} \mathrm{O}_{3}$. Daniels (1991) has calculated that approximately $10 \%$ of the Dokolwayo spinels contain a divalent $\mathrm{CrO}$ component.

The most significant aspect of the kimberlitic spinels reviewed is the $\mathrm{TiO}_{2}$ content. The spinels can be subdivided into two populations, i.e. a $\mathrm{TiO}_{2}$-poor population with $\mathrm{TiO}_{2}<0.7 \mathrm{wt} \%$ and a $\mathrm{TiO}_{2}$-rich population with $\mathrm{TiO}_{2}>0.7 \mathrm{wt} \%$. The $\mathrm{TiO}_{2}$-poor population is further characterized by a $\mathrm{TiO}_{2} / \mathrm{Al}_{2} \mathrm{O}_{3}$ ratio $<0.2$. All diamond inclusion spinels from southern Africa have $\mathrm{TiO}_{2} / \mathrm{Al}_{2} \mathrm{O}_{3}<0.2$. The $\mathrm{TiO}_{2}$ content in the macrocryst spinels commonly exhibit a bimodal frequency distribution reflecting the two observed populations (e.g. Dokolwayo, Figure 1a). 


\section{DISCUSSION}

This study found that there are two major populations of spinels represented in the heavy mineral concentrates of kimberlites, consistent with the observations of Griffin et al. (1994). Based on the $\mathrm{TiO}_{2} / \mathrm{Al}_{2} \mathrm{O}_{3}$ relationship of the spinels it would appear that the $\mathrm{TiO}_{2}$-poor population broadly coincides with the $\mathrm{P} 1$ population and the $\mathrm{TiO}_{2}$-rich spinels coincide with the P2 population of Griffin et al. (1994). However, in contrast with the previous study, both populations are recognized in the mineral concentrates of Group I and Group II kimberlites. The $\mathrm{TiO}_{2}$-poor population of macrocryst spinels are similar in composition to the spinels recovered from diamonds as inclusions and have also been recognized in harzburgitic diamondiferous xenoliths from both Russia and South Africa (Pokhilenko et., 1977; Daniels et al., 1995). This population is therefore interpreted as predominantly derived from the disaggregation of harzburgites and depleted lherzolites from high pressure environments.

The $\mathrm{TiO}_{2}$-rich spinels are clearly not related to the diamond inclusion spinels and therefore have a different genesis. Perhaps the simplest explanation is that these spinels are phenocrysts of the kimberlite magma (Griffin et al., 1994). However, the presence of these spinels in dunites from the Roberts Victor kimberlite (Hatton, 1978) and the occurrence of highly magnesian (F0 95) euhedral olivine inclusions in $\mathrm{TiO}_{2-}$ rich concentrate spinels from Dokolwayo (Daniels and Gurney, 1991) precludes these spinels being related to the kimberlite.

A simple explanation would be that the $\mathrm{TiO}_{2}$-rich spinels represent a portion of the $\mathrm{TiO}_{2}$-poor population that was metasomatised by a $\mathrm{TiO}_{2}$-rich fluid. However, the mechanics of this process should be considered. Diamond inclusion-type spinels and subcalcic chromium-rich garnets (G10) garnets have been found to co-exist in a number of instances (Danchin and Boyd, 1976; Sobolev et al., 1984; Daniels et al;, 1995) and therefore are assumed to have the same paragenesis. It would therefore be reasonable to assume that if a significant proportion of the spinels have been metasomatised by a $\mathrm{TiO}_{2}$-rich fluid, then the effect of this metasomatic event should, to some extent, be manifested in the G10 population of the kimberlite.

Partition coefficients for $\mathrm{TiO}_{2}$ between spinel and ultrabasic liquids and garnet and liquid suggest that the average $\mathrm{TiO}_{2}$ concentration of concentrate $\mathrm{G} 10$ garnets from Dokolwayo should be in the order of $0.55 \mathrm{wt} \%$
$\mathrm{TiO}_{2}$, assuming that the garnets co-existed with the majority of the spinels. However, the maximum $\mathrm{TiO}_{2}$ content observed in Dokolwayo G10 concentrate garnets is $0.17 \mathrm{wt} \%$, similar to the $\mathrm{TiO}_{2}$ contents observed in Finsch concentrate G10 garnets (Daniels, 1991, Gurney and Switzer, 1973). The $\mathrm{TiO}_{2}$ content of the G10 garnets from Dokolwayo do therefore not support a suggestion of re-equilibration against a $\mathrm{TiO}_{2}$ rich metasomatic fluid that would account for the high concentrations of $\mathrm{TiO}_{2}$ in the concentrate spinels.

An alternative explanation is that it may be possible for the $\mathrm{TiO}_{2}$-rich spinels to be derived from a different zone in the mantle to the $\mathrm{TiO}_{2}$-poor garnets and spinels and that the $\mathrm{TiO}_{2}$-rich spinels do indeed represent metasomatised spinels. However, the trends defined by $\mathrm{Ni}$ and $\mathrm{TiO}_{2}$ in these spinels (Griffin et al., 1994) indicate that the $\mathrm{TiO}_{2}$-rich spinels are magmatic in origin. The lack of distinctive $\mathrm{TiO}_{2}$ zonation in these spinels argue against a metasomatic origin. Furthermore, the occurrence of highly magnesian (Fo95) euhedral olivine inclusions in the $\mathrm{TiO}_{2}$-rich concentrate spinels (Daniels and Gurney, 1991) suggests that these spinels are derived from a depleted ultramafic silicate assemblage. The high forsterite content of the olivine inclusions are also inconsistent with a metasomatic origin.

The presence of spinels in komatiite-type liquids have been ascribed to chromium saturation of the melts (Murk and Campbell, 1986). Normal melt - residue relationships between komatiitic melts and the resultant residues can account for the chromium compositions observed in the kimberlite concentrate spinels, including the Dokolwayo spinels with an average of $63.8 \mathrm{wt} \% \quad \mathrm{Cr}_{2} \mathrm{O}_{3}$. However, known komatiite compositions and partition coefficients for spinel/liquid cannot account for the $\mathrm{TiO}_{2}$ contents of the spinels without considering the behaviour of $\mathrm{Ti}^{4+}$ in silicate melts. Spectroscopic data have indicated that $\mathrm{Ti}^{4+}$ can be present in a silicate liquid as titanate complexes and exist in clusters where $\mathrm{Ti}-\mathrm{O}-\mathrm{Ti}$ bonds prevail (Mysen et al., 1980, 1981). These titanate complexes tend to unmix with the silicate melt as depolymerisation of the melt increases. The increased depolymerisation of komatiite-type liquids with increasing temperature and $\mathrm{MgO}$ concentrations would produce strong deviations from ideality, resulting in the formation of titanate complexes. These titanate clusters are structurally similar to submicroscopic, octahedrally coordinated spinelloid aggregates observed in silicate melts (O'Reilly and MacIver, 1962; Fournier et al., 1971). The unmixing of these titanate clusters may increasingly favour the partitioning of titanium into the 
residue. In the absence of a $\mathrm{TiO}_{2}$-rich phase in the residue, it is suggested that these unmixed titanate clusters will preferentially complex with the residual spinel rather than with the orthopyroxene or olivine in the residue. The titaniferous spinels produced under these conditions may be expected to deviate from ideality and be non-stoichiometric.

The model presented above for the genesis of $\mathrm{TiO}_{2}$-rich spinels is consistent with the compositional trends observed in the spinels, the mineral assemblages observed in xenocrysts as well as xenoliths and with a magmatic origin. However, are considered to be constituents of a residue from the extraction of komatiitic melts from the mantle and not related to the kimberlite itself.

Thermobarometry has determined that harzburgitic diamonds crystallise under subsolidus temperature conditions. The co-existence of $\mathrm{TiO}_{2}$-poor spinels, diamonds, olivines, G10-garnets and orthopyroxenes as inclusions in diamonds and as xenoliths determine a common genesis. It is concluded that the $\mathrm{TiO}_{2}$-poor diamond inclusion-type spinels crystallise under subsolidus conditions and do not crystallise from a melt or as part of a residual phase.

\section{REFERENCES}

Danchin, R.V., Boyd, F.R., 1976. Ultramafic nodules from the Premier kimberlite pipe, South Africa. Carnegie Inst. Wash. Yearb., 75, $531-538$.

Daniels, L.R.M., 1991. Diamonds and related minerals from the Dokolwayo kimberlite, Kingdom of Swaziland. Ph.D. Thesis, Univ. Cape Town, Cape Town, South Africa.

Daniels, L.R.M., Gurney, J.J., 1991. Oxygen Fugacity constraints on the southern African lithosphere. Contrib. Mineral. Petrol., 108, 158 - 161.

Daniels, L.R.M., Richardson, S.H., Menzies, A.H., De Bruin, D., Gurney, J.J. (1995) Diamondiferous garnet macrocrysts in the Newlands kimberlite, South Africa - Rosetta stones from the Kaapvaal Craton root. Extended Abstr Sixth International Kimberlite Conf, Novosobirsk, Russia.
Fournier, J.T., Landry, R.J., Bartham, R.H., 1971. ESR exchange coupled $\mathrm{Cr} 3+$ ions in phosphate glass. J. Chem. Phys., 55, $2522-2526$.

Griffin, W.L., Ryan, C.G., Gurney, J.J., Sobolev, N.V., Win, T.T., 1994. Chromite macrocrysts in kimberlites and lamproites: Geochemistry and origin. Proc. Fifth Intl. Kimb. Conf., Vol. 1, Kimberlites, Related Rocks and Mantle Xenoliths, pp. $366-377$.

Gurney, J.J., Switzer, G., 1973. The discovery of garnets closely related to diamonds in the Finsch pipe, South Africa. Contrib. Mineral. Petrol., 39, 103 - 116.

Hatton, C.J., 1978. The geochemistry and origin of xenoliths from the Roberts Victor Mine. Ph.D. Thesis, Univ. Cape Town, Cape Town, South Africa.

Lawless, P.J., 1974. Some aspects of the geochemistry of kimberlite xenocrysts. M. Sc. Thesis, Univ. Cape Town, Cape Town, South Africa.

Mal'kov, B.A., Popova, V., 1972. Chrome spinellids as indicators of the presence of diamonds in Yakutian kimberlite. Doklady Akad. Nauk. SSR, 211, 141 144.

Murck, B.W., Cambell, I.H., 1986. The effects of temperature, oxygen fugacity and melt composition on the behaviour of chromium in basic and ultrabasic melts. Geochim. Cosmochim. Acta. 50, $1871-1887$.

Mysen, B.O., Seifert, F.A., Virgo, D., 1980. Structure and redox equilibria of iron-bearing silicate melts. Am. Mineral. 65, $867-884$.

Mysen, B.O., Virgo, D., Seifert, F.A., 1981. Ferric iron as a network former and as a network modifier in melts relevant to petrological processes. Carnegie Inst. Wash. Yearb. 80, $311-313$.

O'Reilly, D.E., MacIver, D.S., 1962. Electron paramagnetic resonance absorption of chromia-alumina catalysts. J. Phys. Chem., 66, $276-281$.

Pokhilenko, N.P., Sobolev, N.V., Lavrent'ev, Yu.G. 1977. Xenoliths of diamondiferous ultramafic rocks from Yakutian kimberlites. Second Int. Kimb. Conf., Santa Fe, Extended Abstr.

Sobolev, N.V., Pokhilenko, N.P., Efimova, E.S., 1984. Xenoliths of diamond-bearing peridotites in kimberlites and the problem of diamond origin. Geol. Geofiz., 25, $63-80$. 


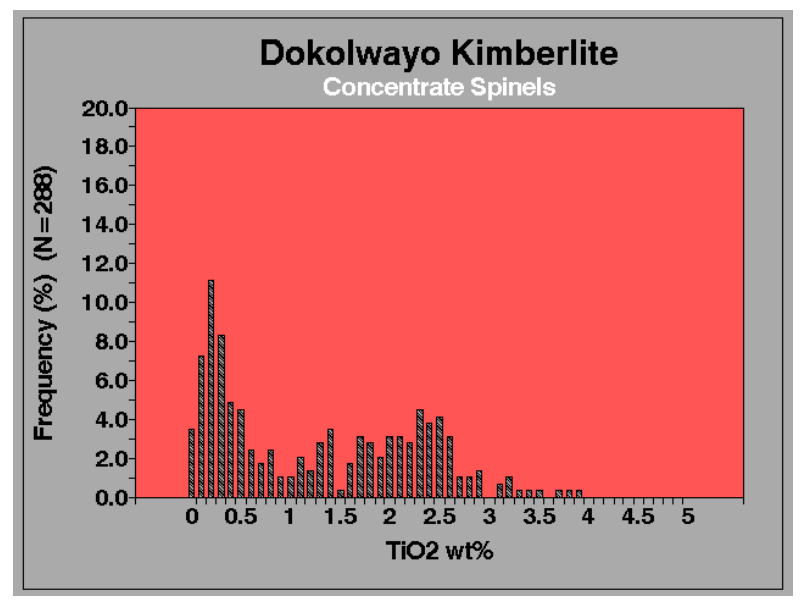

Figure 1a: Frequency of $\mathrm{TiO}_{2}$ concentrations in Dokolwayo spinels.

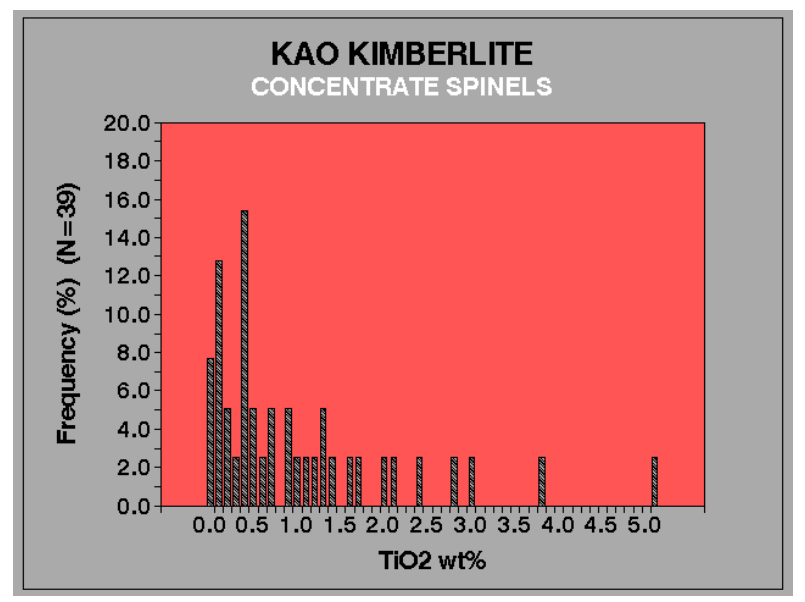

Figure 1b: Frequency of $\mathrm{TiO} 2$ concentrations in Kao spinels.

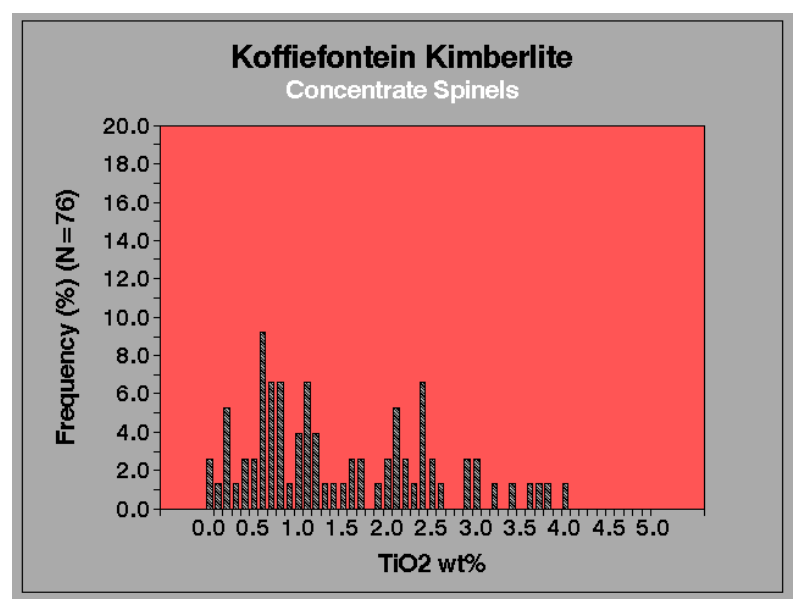

Figure 1c: Frequency of $\mathrm{TiO}_{2}$ concentrations in Koffiefontein spinels.

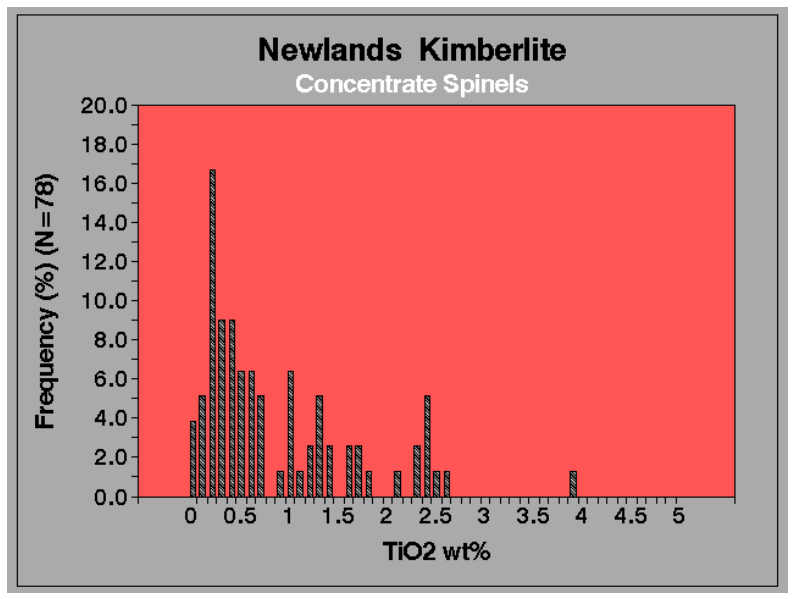

Figure 1d: Frequency of $\mathrm{TiO}_{2}$ concentrations in Newlands spinels.

Table 1: Summary of compositional charcateristics of macrocryst spinels.

\begin{tabular}{|ll|r|r|r|r|}
\hline Location & & Dokolwayo & Kao & Koffiefontein & Newlands \\
$\mathbf{N}$ & & 288 & 39 & 76 & 78 \\
\hline \multirow{3}{*}{ TiO2 } & Minimum & 0.00 & 0.00 & 0.00 & 0.00 \\
& Maximum & 3.89 & 5.25 & 3.95 & 3.82 \\
& Average & 1.22 & 1.00 & 1.44 & 0.82 \\
\hline \multirow{3}{*}{ Al2O3 } & Minimum & 0.70 & 5.52 & 2.71 & 2.88 \\
& Maximum & 29.35 & 24.36 & 14.30 & 20.66 \\
& Average & 5.01 & 11.19 & 6.62 & 7.61 \\
\hline \multirow{3}{*}{ Cr2O3 } & Minimum & 39.44 & 40.48 & 52.74 & 43.42 \\
& Maximum & 73.51 & 64.68 & 67.36 & 64.45 \\
& Average & 63.84 & 55.33 & 60.69 & 59.91 \\
\hline \multirow{3}{*}{ MgO } & Minimum & 8.50 & 8.66 & 10.25 & 6.85 \\
& Maximum & 19.40 & 15.43 & 15.44 & 15.85 \\
& Average & 12.84 & 13.39 & 13.23 & 12.79 \\
\hline
\end{tabular}

